\title{
Rehmannia Root Improves Extracellular Matrix Production and Epidermal Differentiation by Upregulation of the Estrogen Receptor
}

\author{
Keita Shigeyama, Ikuyo Sakaguchi \\ Department of Research \& Development, Club Cosmetics Co., Ltd., Ikoma, Nara, Japan \\ Email: kshigeya@clubcosmetics.co.jp
}

How to cite this paper: Shigeyama, K. and Sakaguchi, I. (2021) Rehmannia Root Improves Extracellular Matrix Production and Epidermal Differentiation by Upregulation of the Estrogen Receptor. Journal of Cosmetics, Dermatological Sciences and Applications, 11, 186-203.

https://doi.org/10.4236/jcdsa.2021.113017

Received: June 4, 2021

Accepted: July 13, 2021

Published: July 16, 2021

Copyright $\odot 2021$ by author(s) and Scientific Research Publishing Inc. This work is licensed under the Creative Commons Attribution International License (CC BY 4.0).

http://creativecommons.org/licenses/by/4.0/

(c) (i) Open Access

\begin{abstract}
Estrogen is essential for the skin to maintain its physiological function. The binding of estrogen to the estrogen receptor (ER) activates gene transcription, which has biological effects on the target tissue. Estrogen levels and ER expression are known to decrease with aging and exposure to ultraviolet light (UV); therefore, increased estrogen levels and ER expression may improve age-related changes in the skin. Rehmannia root has been reported to have blood circulation-promoting and anti-inflammatory effects; however, few studies have reported the effects of Rehmannia root on skin. In this study, we examined the effects of Rehmannia glutinosa Libosch. var. purpurea Makino root extract (RE) on ER expression, and estrogen, RE, or their related ingredients increased ER expression in human epidermal keratinocytes, human dermal fibroblasts, and skin models. Moreover, RE increased the production of basic fibroblast growth factor, transforming growth factor $\beta 1$, and epidermal growth factor. The mixture of estrogen and RE improved extracellular matrix (ECM) production to a greater degree than estrogen and RE independently. Although high population doubling levels (PDL) and UV irradiation downregulated ER expression, RE upregulated ER expression in high PDL cells and UV irradiated cells. In addition, RE increased the expression of epidermal differentiation marker proteins compared to their expression levels in the absence of RE. The collective findings suggest that RE aids in the prevention of skin aging by upregulating the ER expression that has been decreased by aging and UV and promoting estrogen activity, ECM production, and epidermal differentiation.
\end{abstract}

\section{Keywords}

Estrogen Receptor, Skin Aging, Rehmannia Root, Extracellular Matrix, Epidermal Differentiation 


\section{Introduction}

Sex steroid hormones such as estrogen, progesterone, and androgen exhibit a broad spectrum of physiological functions ranging from regulating the menstrual cycle and reproduction to modulation of skin function, bone density, brain function, and cholesterol mobilization. Skin functions are particularly reliant on estrogen because it promotes cell proliferation by increasing cell growth factors and increases the production of hyaluronic acid and collagen, which are involved in skin moisturization and elasticity, lessening wrinkles, and improving skin texture [1] [2] [3] [4]. Bioactive estrogens include estrone (E1), estradiol (E2), and estriol (E3), where E2 is more prolific and has the most significant physiological activity, followed by E1 and E3 [5]. Estrogen mediates its biological effects in target tissues by binding to the estrogen receptor (ER), a specific intracellular receptor. The balance between the two forms of ER, namely ER-alpha $(\mathrm{ER} \alpha)$ and ER-beta $(\mathrm{ER} \beta)$ is suggested to be important for maintaining skin homeostasis. Binding of a ligand, such as estrogen and estrogen-like substances, activates the ER and promotes ER dimerization to produce homodimers of $\operatorname{ER} \alpha$ or $\operatorname{ER} \beta$ individually or the $\operatorname{ER} \alpha$-ER $\beta$ heterodimer. These dimers either bind directly to estrogen response elements of target gene promoters, or indirectly through interaction with other DNA-bound transcription factors, such as activator proteins or specific proteins. After DNA binding, ER dimers regulate gene expression by interacting with cofactors, such as coactivators or corepressors, thereby promoting the production of an extracellular matrix (ECM) comprising hyaluronic acid or collagen, and production of cell growth factors such as basic fibroblast growth factor (bFGF), transforming growth factor $\beta 1$ (TGF- $\beta 1$ ), and epidermal growth factor (EGF) [6] [7] [8] [9]. ERs are expressed in various tissues, including the skin, blood vessels, and brain, whereas $\operatorname{ER} \alpha$ and $\operatorname{ER} \beta$ are also expressed in the epidermis keratinocytes and dermis fibroblasts [10] [11] [12] [13] [14]. The fibroblasts ER is involved in the proliferation of keratinocyte and epidermal formation, and the keratinocytes ER affects the increase of epidermal differentiation marker proteins such as loricrin, involucrin, and transglutaminase- 1 as well as the proliferation of fibroblasts [10] [11] [12]. These observations suggest that the balance of ER expression in each tissue is intimately involved in maintaining tissue homeostasis. Internal and external factors such as aging, menstrual cycle, active oxygen, or exposure to ultraviolet light (UV) reduce estrogen levels and ER expression, contributing to the formation of immature epidermis leading to skin aging features such as wrinkles and sagging [3] [12] [13] [14]. Therefore, increases in estrogen levels and ER expression may improve the age-related changes in the skin; however, few studies have reported that ER expression is increased by crude drugs and cosmetic ingredients.

Rehmannia root is used in traditional Chinese medicines such as Hachimijiogan and Rokumijiogan. Rehmannia root contains large quantities of the iridoid glycoside catalpol and the oligosaccharide stachyose. Additionally, it contains 
the iridoid glycosides aucubin, monomelittoside, and dihydrocatalpol; the oligosaccharides manninotriose and raffinose; and amino acids such as arginine [15]. Although the Rehmannia root has been reported to have blood circulation promoting and anti-inflammatory effects [15], the effects of Rehmannia root on skin aging have not yet been reported. In this study, we examined the effects of Rehmannia glutinosa Libosch. var. purpurea Makino root and its constituents on ER expression in the skin.

\section{Materials and Methods}

\subsection{Reagents}

Estradiol was purchased from Sigma-Aldrich (St. Louis, MO, USA), fetal bovine serum (FBS) was acquired from Thermo Fisher Scientific (Waltham, MA, USA), and rabbit and mouse serum solutions were procured from Nichirei Biosciences (Tokyo, Japan). Rabbit anti-ER $\alpha$ monoclonal antibody labeled with phycoerythrin (PE), mouse anti-ER $\beta$ monoclonal antibody labeled with PE, rabbit anti-loricrin polyclonal antibody, rabbit anti-involucrin polyclonal antibody, and mouse anti-cytokeratin 10 monoclonal antibodies were purchased from Abcam (Cambridge, UK). Thermo Fisher Scientific also provided Alexa Fluor 647-labeled donkey anti-mouse antibody and Alexa Fluor 488-labeled donkey anti-rabbit antibody. Stachyose and catalpol were standard for crude drug determination and were obtained from FUJIFILM Wako Pure Chemical (Osaka, Japan) and used as internal standards. All other chemicals were purchased from FUJIFILM Wako Pure Chemical.

\subsection{Plant Material}

Rehmannia root extract (RE, Lot.06282) was purchased from KOEI KOGYO (Tokyo, Japan). The roots of Rehmannia glutinosa Libosch. var. purpurea Makino were dried, cut into small pieces and extracted with a 1:1 solution of 1,3-butylene glycol and water at $50^{\circ} \mathrm{C}$ for $5 \mathrm{~h}$. The extract was stored at $4^{\circ} \mathrm{C}$ for 3 $\mathrm{d}$, filtered using a $5 \mu \mathrm{m}$ filter.

\subsection{Cell Culture}

Adult normal human dermal fibroblasts (NHDF; Kurabo, Osaka, Japan) were cultured in Dulbecco's modified Eagle's medium (DMEM) supplemented with $10 \% \mathrm{FBS}, 100 \mathrm{U} / \mathrm{mL}$ penicillin, and $100 \mu \mathrm{g} / \mathrm{mL}$ streptomycin. In addition, NHDF displaying a high population doubling levels (PDL) were obtained by subculturing 15 times. Normal human epidermal keratinocytes immortalized by the pSV40 gene (immortalized NHEK; JCRB, Osaka, Japan) were cultured in an MCDB153 medium with growth supplements. Cells were seeded in culture plates and grown to subconfluence in a $5 \% \mathrm{CO}_{2}$ incubator at $37^{\circ} \mathrm{C}$. Reconstructed human epidermal models (LabCyte EPI-MODEL; J-TEC, Aichi, Japan) were pre-cultured in a $5 \% \mathrm{CO}_{2}$ incubator at $37^{\circ} \mathrm{C}$ using the attached assay medium. 


\subsection{UVA Exposure}

NHDF was seeded in LabTek Chamber slides (Thermo Fisher Scientific), cultured, and prior to UVA exposure, the medium was replaced with Hanks' balanced salt solution and the cell was exposed to $0.26 \mathrm{~J} / \mathrm{cm}^{2}$ UVA using a sunlight irradiation system (SERIC, Tokyo, Japan). Sham-UVA irradiated NHDF was shielded from the lamp during UVA exposure.

\subsection{Evaluation of ER Expression in Keratinocytes and Fibroblasts}

Immortalized NHEK and NHDF were seeded in LabTek chamber slides and cultured, after which the medium was replaced with unaltered medium or that containing estrogen or RE, and incubation continued.

Following this, the cells were fixed in formalin and blocked with serum solution. They were then stained with PE-labeled anti-ER $\alpha$ antibody or PE-labeled anti-ER $\beta$ antibody. Cell nuclei were stained with 4,6-diamidino-2-phenylindole dihydrochloride (DAPI). Cell nuclei and ERs fluoresced blue and yellow, respectively, when examined using an IX70 microscope coupled with a DP80 digital camera (Olympus, Tokyo, Japan). Images were acquired using WinROOF2015 image analysis software (Mitani, Fukui, Japan), and the average luminance value was calculated by dividing the luminance value by the cell number. We performed at least three independent studies, yielding similar results, which are shown in the figures.

\subsection{HPLC Analysis}

Stachyose and catalpol were quantified by HPLC analysis using a HITACHI Chromaster (Hitachi High-Tech Science, Tokyo, Japan) coupled to a Chromaster 5430 diode array detector (Hitachi High-Tech Science) and a Chromaster 5450 refractive index detector (Hitachi High-Tech Science).

Analysis was carried out using Shodex Asahipak NH2P-50 4E columns (5 $\mu \mathrm{m}$, $4.6 \times 250 \mathrm{~mm}$, Showa Denko, Tokyo, Japan). For quantification of stachyose and catalpol, a mobile phase consisting of $70 \%(\mathrm{v} / \mathrm{v})$ acetonitrile in water was used at a flow rate of $1 \mathrm{~mL} / \mathrm{min}$ and column temperature of $50^{\circ} \mathrm{C}$. UV detection was performed at a wavelength of $203 \mathrm{~nm}$. The concentrations of stachyose and catalpol were calculated from standard curves of standard stachyose and catalpol solutions, respectively.

\subsection{Cell Viability}

To investigate cell proliferation, immortalized NHEK and NHDF were seeded and cultured. A cell proliferation assay was performed using the Cell Counting Kit-8 (Dojindo, Kumamoto, Japan) according to the manufacturer's instructions.

\subsection{Measurement of ECM and Growth Factors}

NHDF was seeded and cultured, and the supernatants were collected after sam- 
ple treatment. Type I collagen was measured by direct ELISA using an anti-collagen type I rabbit antibody. The hyaluronic acid, bFGF, TGF- $\beta 1$, and EGF contents were measured using the Quantikine ELISA kit of hyaluronic acid, human bFGF, human TGF- $\beta 1$, or EGF (R\&D Systems, Minneapolis, MN, USA), respectively, according to the manufacturer's instructions.

\subsection{Histological Evaluation and Immunohistochemical Staining in the Skin Model}

The skin model was fixed in formalin and embedded in paraffin wax, and the tissues were cut, deparaffinized, and rehydrated. Hematoxylin and eosin (H\&E) staining and immunohistochemical staining were performed according to standard procedures for tissue sections. For direct immunofluorescence, PE-labeled anti-ER $\alpha$ antibody and PE-labeled anti-ER $\beta$ antibody were used, whereas the primary antibodies used for indirect immunofluorescence were anti-loricrin antibody, anti-involucrin antibody, and anti-cytokeratin-10 antibody. The secondary antibody was Alexa Fluor 647-labeled rabbit anti-mouse antibody or Alexa Fluor 488-labeled goat anti-rabbit antibody. Cell nuclei was stained with DAPI. Cell nuclei, ERs, loricrin, involucrin, and cytokeratin-10 were observed in cells using an IX70 microscope coupled with a DP80 digital camera (Olympus). We performed at least three independent studies, which yielded similar results. A representative experiment is shown in the figures.

\subsection{Statistical Analysis}

The experimental data were evaluated for statistical significance using Student's $t$-test (two-tailed). A $p$ value $<0.05$ was considered statistically significant. Data are expressed as mean $\pm \mathrm{SD}$.

\section{Results}

\subsection{Effect of Estrogen and RE on ER Expression}

Estrogen can increase the expression of ER [16] [17], which may enhance its effect, and binding to the ER improves cell proliferation in the skin. Therefore, the effect of estrogen or RE on ER expression was evaluated using NHDF. First, the biotoxicity of $\mathrm{E} 2$ and RE were evaluated, and biotoxicity was observed at $500 \mu \mathrm{M}$ $\mathrm{E} 2$ and $800 \mu \mathrm{g} / \mathrm{mL}$ RE. Therefore, the effects on ER expression and cell proliferation were evaluated at concentrations lower than $500 \mu \mathrm{M}$ E2 and $800 \mu \mathrm{g} / \mathrm{mL}$ RE. And it was found that E2 upregulated ER $\alpha$ and $\mathrm{ER} \beta$ expression in NHDF, reaching a maximum at $50 \mu \mathrm{M}$ of E2. RE also upregulated ER $\alpha$ and $\mathrm{ER} \beta$ expression to a maximum of $80 \mu \mathrm{g} / \mathrm{mL}$ of RE (Figure $1(\mathrm{~A})$ ). In addition, the $50 \mu \mathrm{M}$ E2 treatment significantly upregulated the ER fluorescence intensity, whereas treatments with $10 \mu \mathrm{M}$ and $100 \mu \mathrm{M}$ E2 did not affect ER expression (Figure 1(B)). Similarly, the ER fluorescence intensity after RE treatment of $80 \mu \mathrm{g} / \mathrm{mL}$ was significantly upregulated, whereas other concentrations of RE did not affect the expression of ER (Figure 1(B)). We evaluated the effect of ER upregulation 
on cell proliferation and determined that E2 did not affect cell proliferation, although treatment with $80 \mu \mathrm{g} / \mathrm{mL}$ RE significantly promoted cell proliferation by upregulation of the ER. In contrast, other concentrations of RE did not affect cell proliferation since the ER was not regulated (Figure 1(C)).

(A)
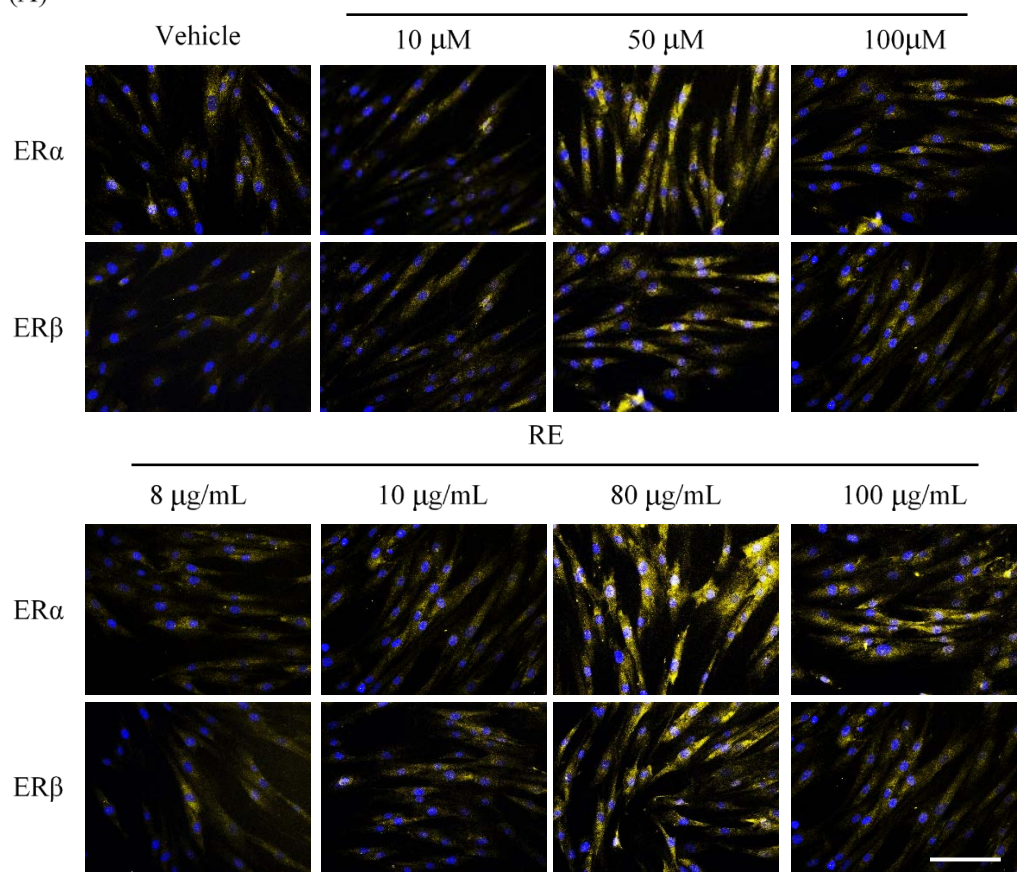

(B)

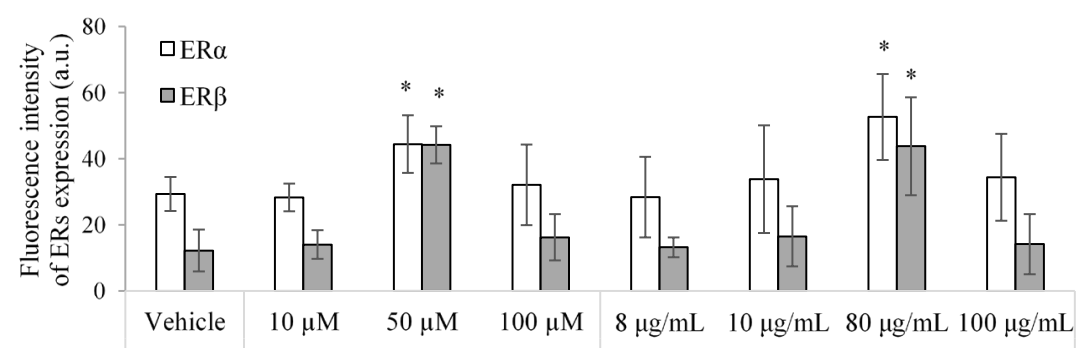

(C)

E2

$\mathrm{RE}$

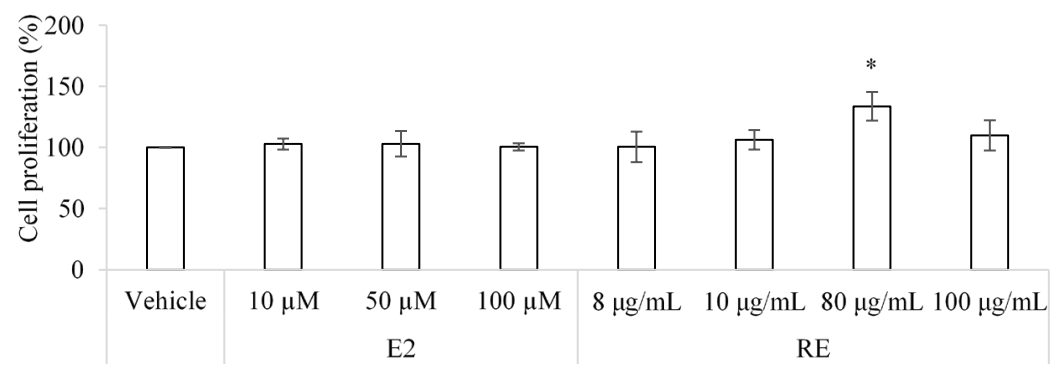

Figure 1. Effect on ER expression and cell proliferation by E2 and RE. (A) Representative merged images of ER $\alpha$ (yellow) and ER $\beta$ (yellow) expression in NHDF treated with samples (blue denotes DAPI-stained cell nuclei). Scale bar, $100 \mu \mathrm{m}$. (B) Changes in the fluorescence intensity of $\mathrm{ER} \alpha$ (open) or $\mathrm{ER} \beta$ (filled) expression in NHDF. (C) Changes in the cell proliferation of NHDF treated with samples. Data are presented as the mean \pm SD $(\mathrm{n}=3) .{ }^{*} p<0.05$ versus ER $\alpha$ of vehicle or ER $\beta$ of vehicle, compared by Student's $t$-test. 


\subsection{Effect of Components in RE on ER Expression}

To evaluate the effect of stachyose and catalpol on ER upregulation, the concentrations of stachyose and catalpol were measured using HPLC. The $80 \mu \mathrm{g} / \mathrm{mL}$ RE contained $15 \mu \mathrm{M}$ stachyose and $2.8 \mu \mathrm{M}$ catalpol. Therefore, we evaluated the effects of $15 \mu \mathrm{M}$ stachyose and $2.8 \mu \mathrm{M}$ catalpol on ER expression and cell proliferation and observed that $15 \mu \mathrm{M}$ stachyose upregulated ER $\alpha$ and $\operatorname{ER} \beta$ expression in NHDF (Figure 2(A)); however, $2.8 \mu \mathrm{M}$ catalpol did not affect ER expression. We then evaluated the effect of ER upregulation on cell proliferation. The results indicated that $15 \mu \mathrm{M}$ stachyose promoted cell proliferation in NHDF (Figure 2(B)), whereas the $2.8 \mu \mathrm{M}$ catalpol had no effect. These results suggest that ER upregulation by RE is activated by stachyose. In fact, cell proliferation by stachyose was similar to the proliferation by RE.

\subsection{Effect of RE on the Time-Dependent Changes in ER Expression and Growth Factors}

The dermis ER is involved in the production of cell growth factors such as bFGF, TGF- $\beta 1$, and EGF and is considered crucial for maintaining dermis function. We investigated whether RE enhances ER expression in NHDF and found that stimulation with $80 \mu \mathrm{g} / \mathrm{mL}$ RE upregulated ER $\alpha$ and ER $\beta$ after $24 \mathrm{~h}$, significantly promoted cell proliferation by ER upregulation. Accordingly, we evaluated the time-dependent changes in cell proliferation, ER expression and cell growth factors production using NHDF. The cell proliferation increased in the vehicle and $80 \mu \mathrm{g} / \mathrm{mL} \mathrm{RE}$ in a time-dependent manner, and cell proliferation of RE treatment significantly increased compared to that in the vehicle between $18 \mathrm{~h}$ and 24 $\mathrm{h}$ (Figure 3(A)). In addition, ER expression increased in the vehicle and 80 $\mu \mathrm{g} / \mathrm{mL} \mathrm{RE}$ in a time-dependent manner, and ER expression of RE treatment significantly increased compared to that in the vehicle between $6 \mathrm{~h}$ and $24 \mathrm{~h}$ (Figure $3(\mathrm{~B})$ ). The production of bFGF was most increased by vehicle and 80 $\mu \mathrm{g} / \mathrm{mL} \mathrm{RE}$ at $9 \mathrm{~h}$, and the bFGF production of RE treatment significantly increased compared with that of the vehicle between $9 \mathrm{~h}$ and $24 \mathrm{~h}$ (Figure 3(C)). TGF- $\beta 1$
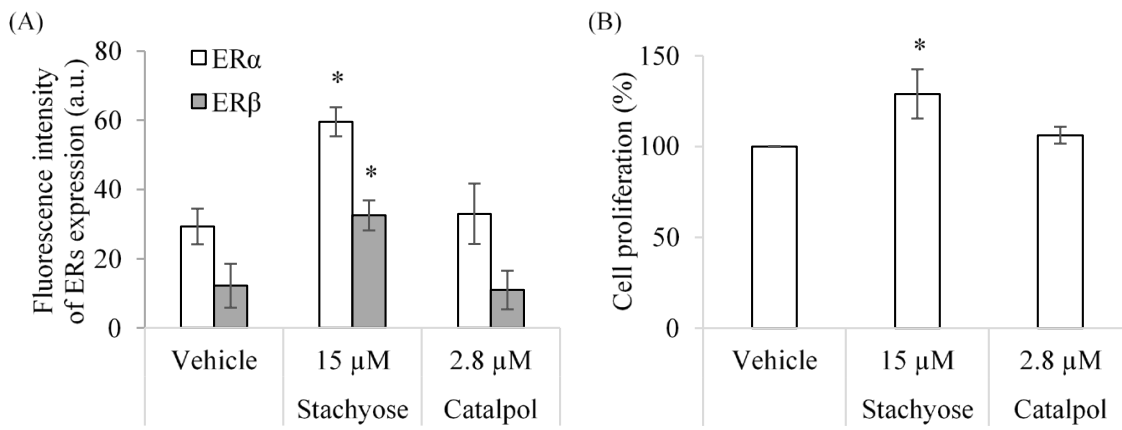

Figure 2. Effect on ER expression and cell proliferation by ingredients in RE. (A) Changes in the fluorescence intensity of $\mathrm{ER} \alpha$ (open) or $\mathrm{ER} \beta$ (filled) expression in NHDF treated with stachyose or catalpol. (B) Changes in the cell proliferation of NHDF treated with stachyose or catalpol. Data are presented as the mean $\pm \mathrm{SD}(\mathrm{n}=3) .{ }^{\star} p<0.05$ versus ER $\alpha$ of vehicle or $\mathrm{ER} \beta$ of vehicle, compared by Student's $t$-test. 
(A)

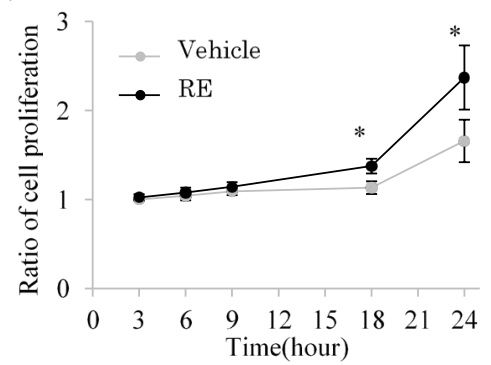

(C)

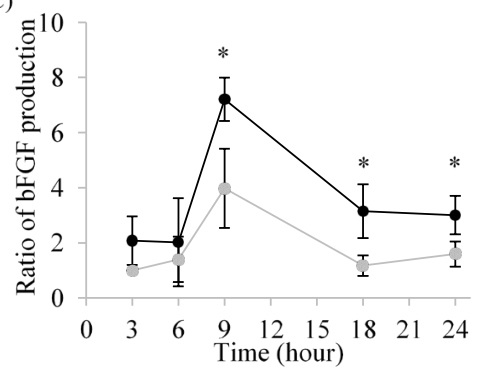

(E)

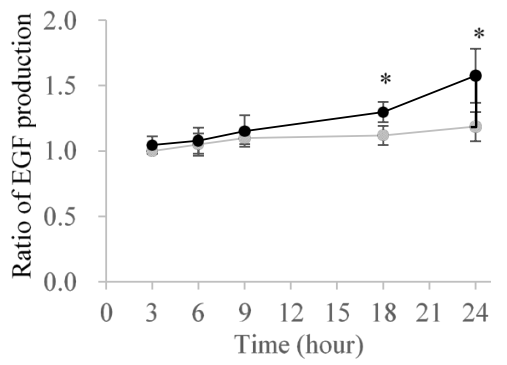

(B)

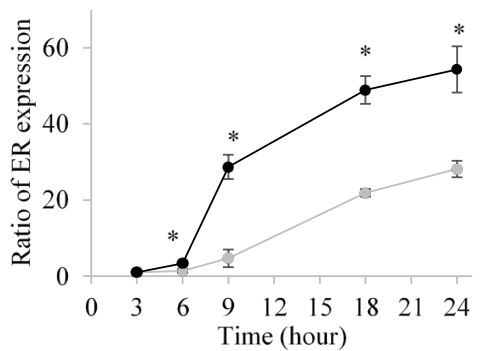

(D)

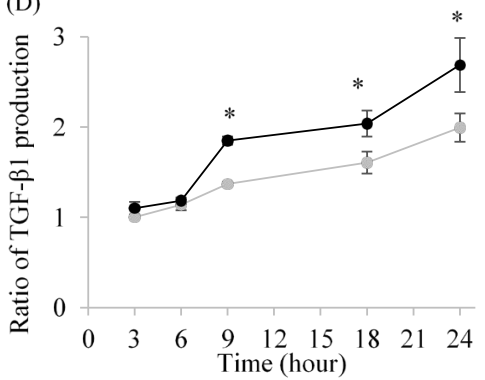

Figure 3. Effect on the time-dependent change of ER expression and cell growth factor production by RE. (A)-(B) Changes in the cell proliferation (A) and ER expression fluorescence intensity (B) in the vehicle and $80 \mu \mathrm{g} / \mathrm{mL}$ RE. (C)-(E) Changes in the production of bFGF (C), TGF- $\beta 1$ (D), or EGF (E) in the vehicle and $80 \mu \mathrm{g} / \mathrm{mL}$ RE. Data are expressed as the ratio of increase relative to the vehicle for $3 \mathrm{~h}$, and are presented as the mean $\pm \mathrm{SD}(\mathrm{n}=3)$. An $*$ indicates a significant difference within the vehicle for the same time point.

production increased with the vehicle and $80 \mu \mathrm{g} / \mathrm{mL}$ RE in a time-dependent manner, and the TGF- $\beta 1$ production of RE significantly increased compared with the vehicle between $9 \mathrm{~h}$ and $24 \mathrm{~h}$ (Figure 3(D)). Moreover, the $80 \mu \mathrm{g} / \mathrm{mL}$ $\mathrm{RE}$ treatment increased EGF production in a time-dependent manner, and the EGF production of RE treatment significantly increased compared with that of the vehicle between $18 \mathrm{~h}$ and $24 \mathrm{~h}$ (Figure $3(\mathrm{E})$ ).

\subsection{Effect of Upregulated ER on Estrogen Effects}

The formulation of cell growth factor by estrogen is related to ECM production and cell proliferation, and is considered crucial for maintaining dermal elasticity. To evaluate whether upregulation of ER improved the estrogen effect, we evaluated cell proliferation and ECM production. Treatment with $80 \mu \mathrm{g} / \mathrm{mL} \mathrm{RE}$ increased cell proliferation in NHDF, while $10 \mu \mathrm{M}$ E2 did not affect cell proliferation. Furthermore, cell proliferation was improved by the E2 and RE mixture 
and was significantly greater than that by E2 or RE separately (Figure 4(A)). In addition, $80 \mu \mathrm{g} / \mathrm{mL}$ RE increased hyaluronic acid production in NHDF, whereas $10 \mu \mathrm{M}$ E2 had no effect on this production. Similar to the results for cell proliferation, the $\mathrm{E} 2$ and $\mathrm{RE}$ mixture improved hyaluronic acid production significantly more than E2 or RE alone (Figure 4(B)). Collagen production returned correlating results, in that $80 \mu \mathrm{g} / \mathrm{mL}$ RE increased type I collagen production in NHDF, whereas $10 \mu \mathrm{M}$ E2 had no effect, and the E2 and RE mixture was superior to E2 or RE individually at improving collagen production (Figure $4(\mathrm{C})$ ). These results may reflect the improved estrogen action due to ER upregulation of RE.

\subsection{Effect of RE on ER Downregulation by Increasing PDL}

Aging and photoaging can cause wrinkles and sagging in the skin because they reduce ER expression and decrease the production of hyaluronic acid and collagen [3] [13] [14]. We evaluated the effects on ER expression, cell proliferation, and ECM production using NHDF with different PDLs. Although high PDL cells reduced the expression of $\mathrm{ER} \alpha$ and $\mathrm{ER} \beta$ compared to low PDL cells, treatment with $80 \mu \mathrm{g} / \mathrm{mL}$ RE significantly upregulated the ER fluorescence intensity in the high PDL cells and low PDL cells (Figure 5(A), Figure 5(B)). In addition, the high PDL cells decreased cell proliferation, hyaluronic acid and type I collagen production compared to low PDL cells. In contrast, RE treatment significantly increased cell proliferation and hyaluronic acid and type I collagen production in the high PDL cells and low PDL cells (Figures 5(C)-(E)).
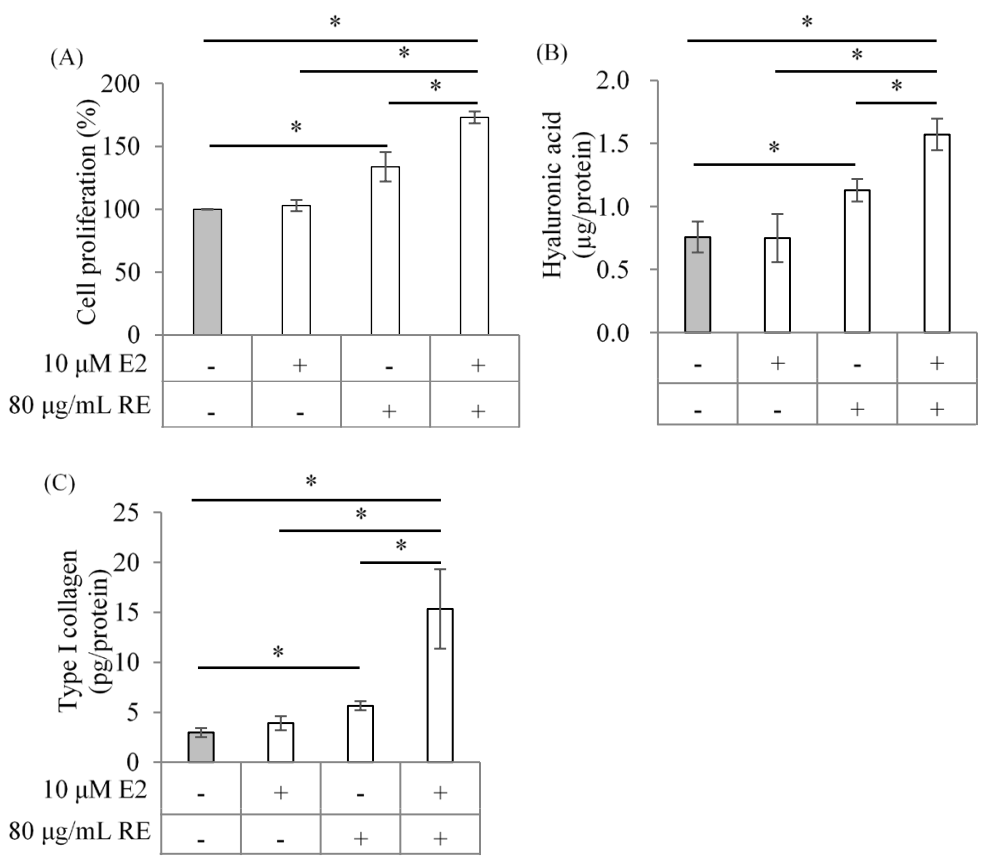

Figure 4. Effect of ER upregulation by RE on cell proliferation and ECM production. (A) Changes in cell proliferation of NHDF treated by either or both $10 \mu \mathrm{M}$ E2 or $80 \mu \mathrm{g} / \mathrm{mL}$ RE. (B) (C) Changes in the hyaluronic acid (B) and the type I collagen $(C)$ production of NHDF treated by either or both $10 \mu \mathrm{M}$ E2 or $80 \mu \mathrm{g} / \mathrm{mL}$ RE. Data are presented as the mean $\pm \mathrm{SD}(\mathrm{n}=3) .{ }^{\star} p<0.05$. 


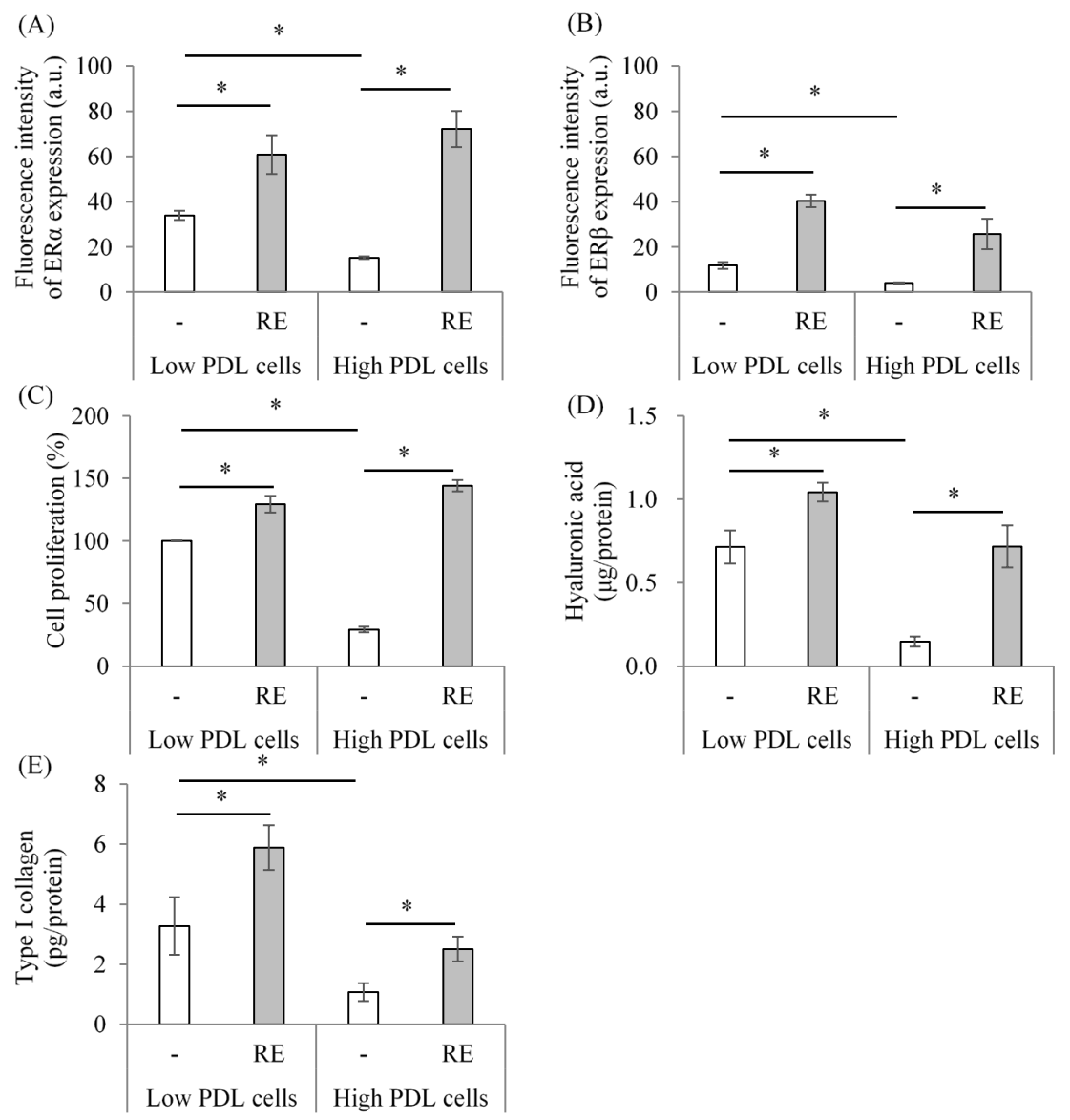

Figure 5. Effect on ER expression, cell proliferation, and ECM production in NHDF with different PDL. (A) (B) Changes in fluorescence intensity of $\operatorname{ER} \alpha$ (A) and $\operatorname{ER} \beta$ (B) expression in low PDL cells and high PDL cells treated with $80 \mu \mathrm{g} / \mathrm{mL}$ RE. (C) Changes in the cell proliferation of low PDL cells and high PDL cells treated with 80 $\mu \mathrm{g} / \mathrm{mL}$ RE. (D) (E) Changes in the production of hyaluronic acid (D) and type I collagen (E) in low PDL cells and high PDL cells treated with $80 \mu \mathrm{g} / \mathrm{mL}$ RE. Data are presented as the mean $\pm \mathrm{SD}(\mathrm{n}=3) .{ }^{\star} p<0.05$.

\subsection{Effect of RE on ER Downregulation by UVA Irradiation}

UV radiation through sunlight is a strong accelerator of skin aging, and is termed photoaging. UVA is known to be responsible for the progression of photoaging because it directly affects dermal fibroblasts. Thus, we evaluated the effects on ER expression, cell proliferation, and production of ECM using NHDF irradiated with UVA. Although the expression of $\operatorname{ER} \alpha$ and $\operatorname{ER} \beta$ were downregulated by UVA irradiation, RE treatment significantly upregulated the ER fluorescence intensity in the UVA irradiated cells and sham-UVA irradiated cells (Figure 6(A), Figure 6(B)). In addition, cell proliferation was decreased by UVA irradiation, although when both cells were treated with $\mathrm{RE}$, the proliferation significantly increased (Figure $6(\mathrm{C})$ ). Moreover, the production of hyaluronic acid and type I collagen similarly lowered by UVA irradiation, whereas RE treatment significantly increased the production of hyaluronic acid and type I collagen in the UVA irradiated cells and sham-UVA irradiated cells (Figure 6(D), Figure 6(E)). 

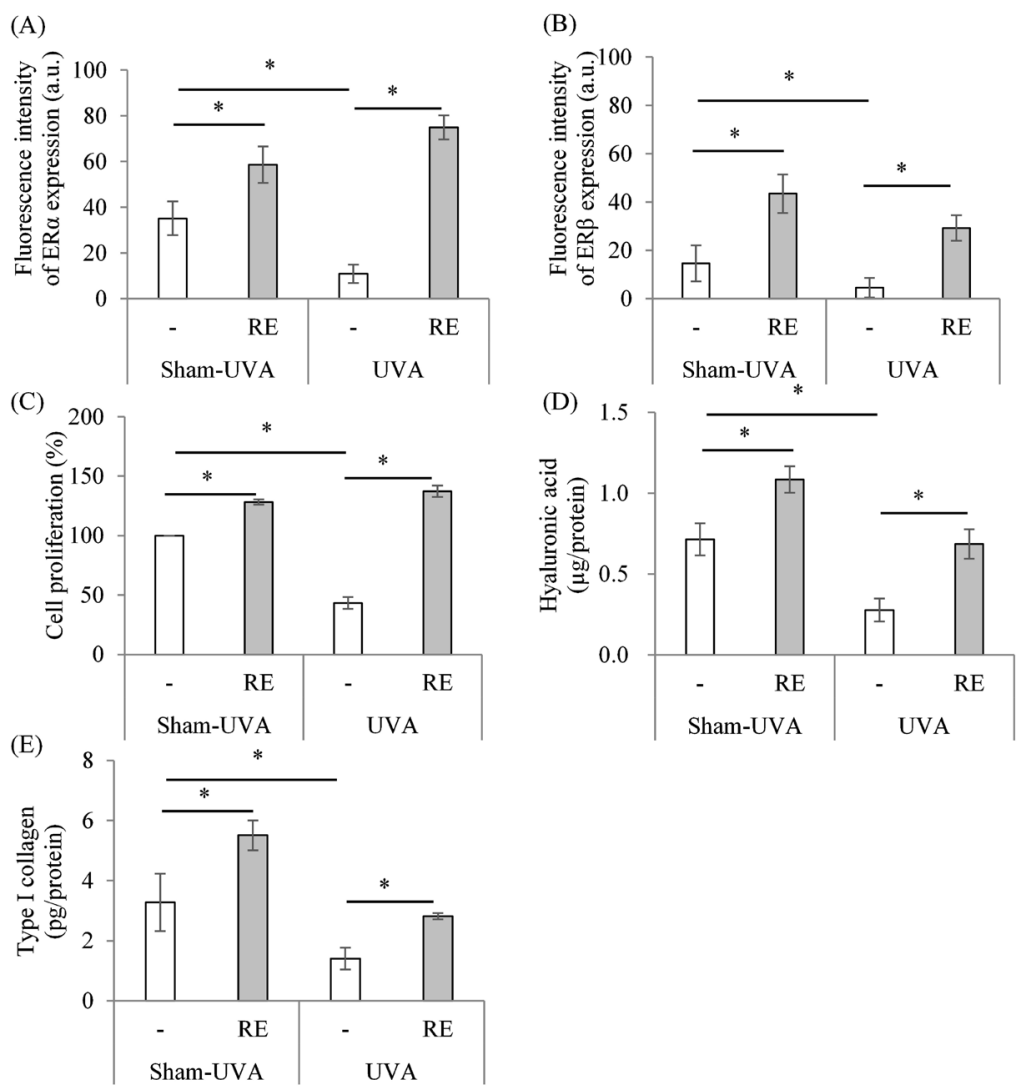

Figure 6. Effect on ER expression, cell proliferation, and ECM production in NHDF by UVA irradiation. (A) (B) Changes in fluorescence intensity of ER $\alpha$ (A) and ER $\beta$ (B) expression in sham-UVA irradiated cells and UVA irradiated cells treated with $80 \mu \mathrm{g} / \mathrm{mL}$ RE. (C) Changes in the cell proliferation of UVA irradiated cells treated with $80 \mu \mathrm{g} / \mathrm{mL}$ RE. (D) (E) Changes in the production of hyaluronic acid (D) and type I collagen (E) in sham-UVA irradiated cells and UVA irradiated cells treated with $80 \mu \mathrm{g} / \mathrm{mL}$ RE. Data are presented as the mean $\pm \mathrm{SD}(\mathrm{n}=3) .{ }^{\star} p<0.05$.

\subsection{Effect of RE on ER Expression and Cell Proliferation in Immortalized NHEK}

The epidermal ER is involved in epidermal differentiation and is considered crucial for maintaining epidermal homeostasis [12]. We investigated whether RE enhances ER expression in NHDF and found that stimulation with RE upregulates ERs. Thus, we evaluated the effect of RE on the epidermal ER using immortalized NHEK. The results showed that $50 \mu \mathrm{M}$ E2 upregulated $\mathrm{ER} \alpha$ and $\mathrm{ER} \beta$ expression in NHDF; however, $10 \mu \mathrm{M}$ E2 did not affect ER expression. Similarly, $80 \mu \mathrm{g} / \mathrm{mL}$ RE upregulated ER $\alpha$ and ER $\beta$ expression in immortalized NHEK, but $8 \mu \mathrm{g} / \mathrm{mL}$ had no effect (Figure $7(\mathrm{~A})$ ). In addition, the ER fluorescence intensity after E2 treatment was significantly upregulated by treatment with $50 \mu \mathrm{M}$ E2. In contrast, treatment with $10 \mu \mathrm{M}$ E2 did not affect the ER expression. The ER fluorescence intensity was significantly upregulated after RE treatment with 80 $\mu \mathrm{g} / \mathrm{mL}$ RE, but treatment with $8 \mu \mathrm{g} / \mathrm{mL}$ again had no effect (Figure $7(B)$ ). Next, we evaluated the effect of ER upregulation on cell proliferation. E2 did not affect cell proliferation. Treatment with $80 \mu \mathrm{g} / \mathrm{mL} \mathrm{RE}$ significantly promoted cell pro- 
liferation by upregulating ER. In contrast, treatment with $8 \mu \mathrm{g} / \mathrm{mL}$ RE did not affect cell proliferation (Figure $7(\mathrm{C})$ ). The results of NHEK coincided with the effect of ER upregulation on NHDF. These results suggest that RE activates the epidermis and dermis.

\subsection{Effect of RE on ER Expression and Epidermal Differentiation in a Reconstructed Human Epidermal Model}

Epidermal ER is considered crucial for maintaining epidermal homeostasis. We investigated immortalized NHEK and RE and found that ERs were upregulated in NHEK following RE stimulation. Accordingly, we evaluated the time-dependent changes in ER expression and localization using a reconstructed human epidermal model, which revealed that RE increased ER expression in the skin model in a time-dependent manner. Interestingly, ER expression was observed in the stratum corneum from the basal layer of $\operatorname{ER} \alpha$ and in the stratum corneum from the granular layer of $\mathrm{ER} \beta$ (Figure 8(A)).
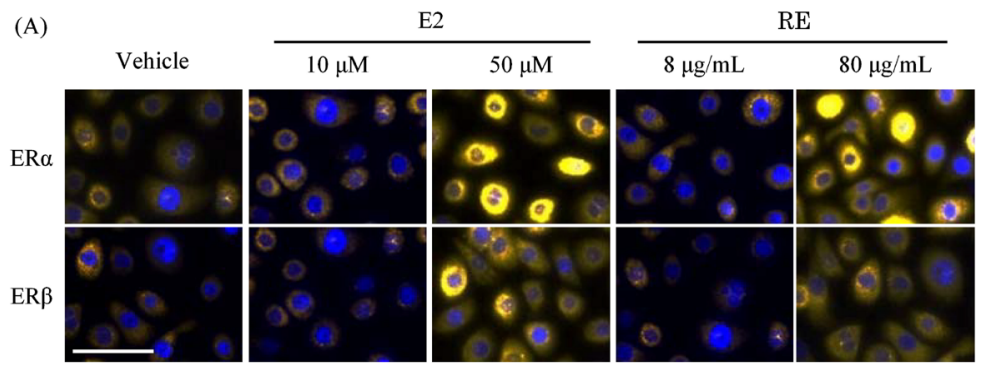

(B)

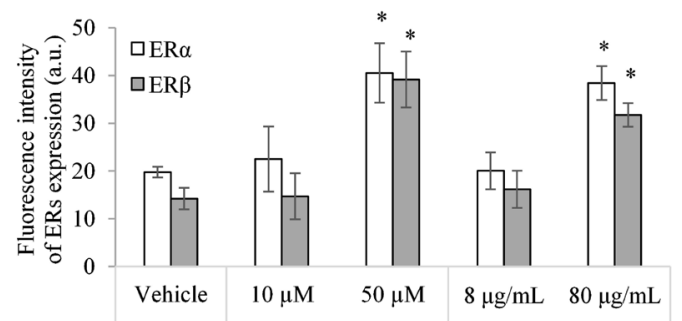

(C)
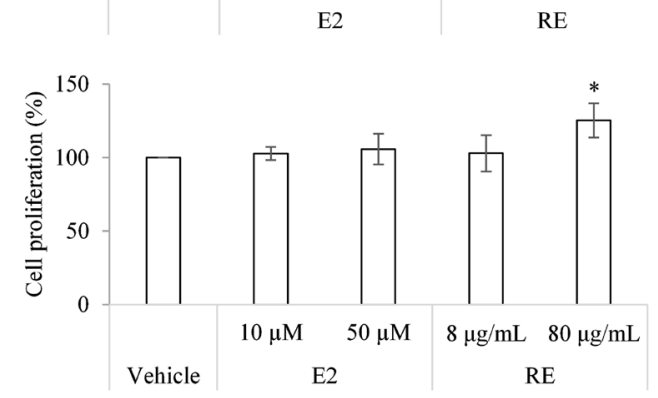

Figure 7. Effect of RE on ER expression and cell proliferation in immortalized NHEK. (A) Representative merged images of $\mathrm{ER} \alpha$ (yellow) and $\operatorname{ER} \beta$ (yellow) expression in immortalized NHEK treated with samples (blue denotes DAPI-stained cell nuclei). Scale bar, $100 \mu \mathrm{m}$. (B) Changes in the fluorescence intensity of ER $\alpha$ (open) or ER $\beta$ (filled) expression in immortalized NHEK. Data are presented as the mean $\pm \mathrm{SD}(\mathrm{n}=3) .{ }^{*} p<$ 0.05 versus ER $\alpha$ of vehicle or ER $\beta$ of vehicle, compared by Student's $t$-test. (C) Changes in the cell proliferation of immortalized NHEK treated with samples. Data are presented as the mean $\pm \mathrm{SD}(\mathrm{n}=3) .{ }^{*} p<0.05$ versus vehicle, compared by Student's $t$-test. 


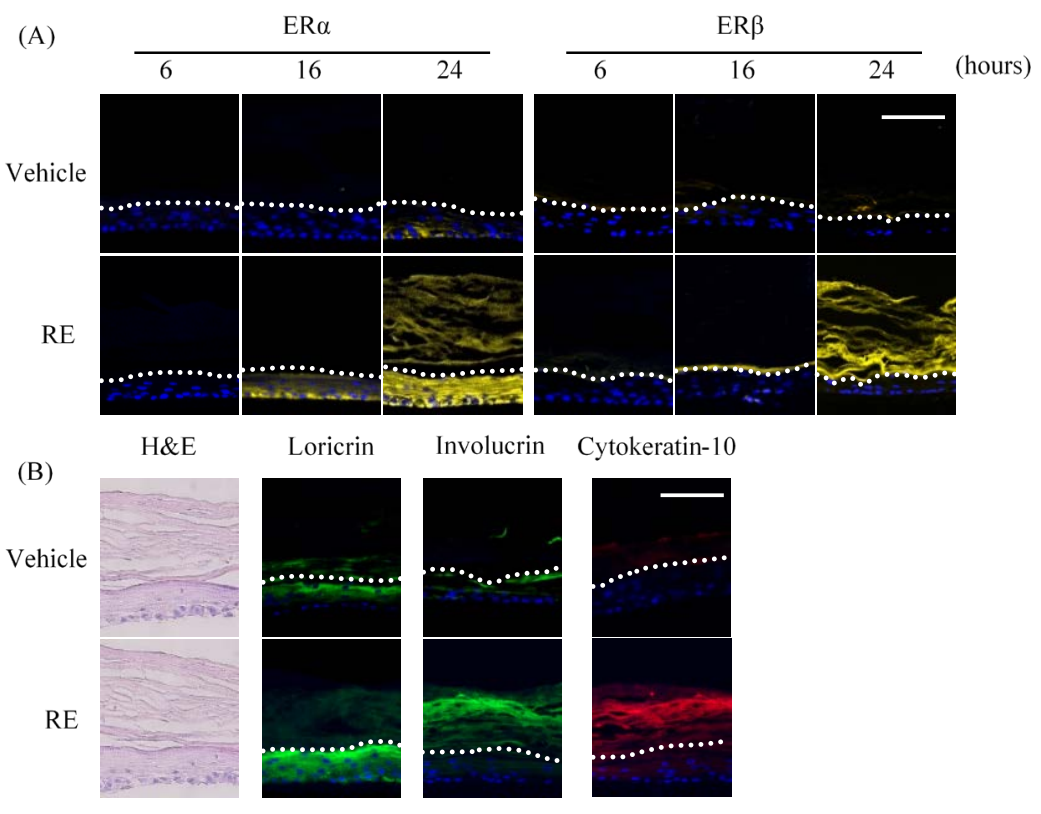

Figure 8. Effect of RE on ER expression or epidermal differentiation in skin model. (A) Representative merged images of $\operatorname{ER} \alpha$ (yellow) and $\operatorname{ER} \beta$ (yellow) expression in the reconstructed human epidermal model (blue denotes DAPI-stained cell nuclei). Scale bar, $100 \mu \mathrm{m}$; white dotted lines indicate the bottom line of the stratum corneum. (B) Representative images of loricrin (green), involucrin (green), and cytokeratin-10 (red) in the reconstructed human epidermal model (blue denotes DAPI-stained cell nuclei). Scale bar, $100 \mu \mathrm{m}$; white dotted lines indicate the bottom line of the stratum corneum.

Furthermore, we evaluated the influence of ER upregulation on the expression of the epidermal differentiation markers loricrin, involucrin, and cytokeratin-10, to evaluate the influence of ER upregulation on epidermal differentiation. RE promoted the expression of loricrin, involucrin, and cytokeratin-10 proteins compared to their expression in the vehicle (Figure 8(B)).

\section{Discussion}

Estrogen binds to the ER inducing different effects on the skin. It is particularly important for the physiological functions of skin because it promotes cell proliferation by increasing cell growth factors, and enhances the production of hyaluronic acid and collagen involved in moisturization and elasticity of the skin, lessening wrinkles, and improving skin texture [1] [2] [3] [4]. However, estrogen levels and ER expression are reduced by aging and UV exposure [3] [13] [14], which in turn reduces the production of ECM and can cause wrinkling and sagging of the skin. Therefore, increases in estrogen levels and ER expression may improve age-related changes in the skin. However, few studies have reported on the ER expression increase by crude drugs and cosmetic ingredients. In this study, we examined the effects of RE and its constituents on ER expression in the skin.

First, we examined whether estrogen or RE enhanced ER expression and confirmed the upregulation of ER expression by $50 \mu \mathrm{M}$ E2 and $80 \mu \mathrm{g} / \mathrm{mL} \mathrm{RE}$ in 
NHDF (Figure 1(A), Figure 1(B)). Furthermore, in terms of cell proliferation, E2 did not affect cell proliferation, although it was significantly promoted by 80 $\mu \mathrm{g} / \mathrm{mL}$ RE by the upregulation of ER (Figure $1(\mathrm{C})$ ). The ER $\alpha$ fluorescence intensity after treatment with $50 \mu \mathrm{M}$ E2 was similar to that of ER $\beta$; however, after treatment with $80 \mu \mathrm{g} / \mathrm{mL} \mathrm{RE}$, the $\mathrm{ER} \alpha$ fluorescence intensity was higher than that of $\operatorname{ER} \beta$ (Figure $1(B)$ ). A balance between $\operatorname{ER} \alpha$ and $\operatorname{ER} \beta$ is important for cell proliferation, and cell proliferation is greater when $\operatorname{ER} \alpha$ is higher than $\operatorname{ER} \beta$ because $\mathrm{ER} \alpha$ promotes cell proliferation, whereas $\mathrm{ER} \beta$ prevents it [18] [19] [20]. Therefore, it was suggested that RE treatment promoted cell proliferation because the expression level of $\mathrm{ER} \alpha$ was higher than that of $\mathrm{ER} \beta$.

The effects of stachyose and catalpol, which are the main components of RE, on ER expression and cell proliferation were evaluated, and stachyose was found to upregulate ER and promote cell proliferation (Figure 2), but catalpol had no effect. These results suggest that stachyose in RE upregulated the ER. Stachyose is a tetrasaccharide consisting of two galactose units, one glucose unit, and one fructose unit. Oligosaccharides are known to promote the production of growth factors and cell proliferation by being internalized by cells [21] [22]. We also evaluated the effects of the saccharide components of stachyose on ER expression and cell proliferation and found that the disaccharides melibiose, the trisaccharide raffinose, and manninotriose upregulate ER expression and promote cell proliferation. However, the monosaccharides in stachyose, such as galactose, glucose, and fructose, exerted no effect (data not shown). Therefore, the disaccharide constituents may be vital for the upregulation of ER by stachyose.

In addition, estrogens are known to bind to the ER, promote the production of various components, and maintain physiological functions of the skin [16] [17]. Furthermore, estrogen activates ER by binding to specific intracellular ERs and promotes ER dimerization [7] [8]. The ER dimer stimulates the production of cell growth factors and cell proliferation by binding to DNA binding sites and regulating gene expression [6] [7] [8] [9] [12]. Thus, we evaluated the time-dependent changes in cell proliferation, ER expression and growth factors production since ER upregulation promoted cell proliferation. It appeared that bFGF and TGF- $\beta 1$ production were improved at $9 \mathrm{~h}$, and EGF production was improved at $18 \mathrm{~h}$ due to the production of growth factors by estrogen, which was enhanced through ER upregulation (Figure 3 ). The bFGF, TGF- $\beta 1$, and EGF are known to regulate the cell cycle, and bFGF and TGF- $\beta 1$ regulate the G0 phase to G1 phase, and EGF regulates S phase to M phase [23] [24] [25]. Thus, RE promoted growth factor production by upregulation of ER and promoted cell proliferation by advancing the cell cycle.

The production of cell growth factor is involved in ECM production and is considered crucial for maintaining the dermis elasticity. These events may occur because the effects of estrogen are improved by ER upregulation of RE, as we observed. Hence, we treated NHDF with a mixture of E2 and RE and evaluated their effect on cell proliferation and ECM production. ER upregulation improves the physiological activity of estrogen and promotes cell proliferation and ECM 
production. These effects were more pronounced than those observed with E2 alone or RE alone (Figure 4). ER is activated by the binding of a ligand such as estrogen, forming a dimeric ER, and translocating into the nucleus. After nuclear translocation, the dimeric ER binds to an estrogen receptor response element, which is an ER-binding region on DNA, and activates gene transcription. Thereafter, the production of growth factors and estrogen finger proteins, as well as ECM proteins such as hyaluronic acid and collagen, is stimulated [6] [7] [8] [9]. Therefore, RE increased the production of ECM by increasing the production of growth factors through ER upregulation, suggesting that ER upregulation of RE reflects an improvement in the biological effects of estrogen.

Furthermore, aging and photoaging reduce ER expression and may cause wrinkles and sagging of the skin [3] [13] [14]. Thus, we evaluated the effects of ER upregulation and ECM production by $\mathrm{RE}$ on aging and photoaging. $\mathrm{Al}$ though ERs expression were downregulated in high PDL cells or UVA irradiated cells, the RE treatment significantly upregulated the ER fluorescence intensity in the high PDL cells or UVA irradiated cells. Moreover, the cell proliferation and ECM production were decreased in high PDL cells or UVA irradiated cells, whereas RE treatment significantly increased the cell proliferation and ECM production in the high PDL cells or UVA irradiated cells (Figure 5, Figure 6). DNA damage induced by aging and photoaging arrests cell cycle progression through the expression of $\mathrm{p} 53, \mathrm{p} 16^{\mathrm{INK4a}}$, and $\mathrm{p} 21^{\mathrm{WAF} 1 / \mathrm{CIP} 1}$. Senescence-associated secretory phenotype (SASP) factors, such as interleukin (IL)-6 and IL-8, spread inflammation in cells and tissues near senescent cells, thereby inducing a variety of age-related pathologies [26] [27]. Therefore, cellular senescence is considered to have harmful effects. In addition, ER decreases SASP factors such as IL-6 by binding with estrogen, and the increased ER $\alpha$ and decreased ER $\beta$ promote cell cycle progression through cyclin D activation [18] [19] [20] [26] [27]. Rehmannia root mitigates cell aging by decreasing p53 and p $16^{\text {INK4a }}$ levels in senescent cells [28], possibly because these components reduce SASP factors, such as IL-6, by regulating the balance between ER $\alpha$ and ER $\beta$. From these facts, it was hypothesized that Rehmannia root could ameliorate the damage caused by aging and photoaging.

Epidermal ER is involved in epidermal differentiation and likely maintains epidermal homeostasis [12]. We evaluated the time-dependent changes in ER expression or localization using immortalized NHEK and a reconstructed human epidermal model. The results showed that $50 \mu \mathrm{M}$ E2 and $80 \mu \mathrm{g} / \mathrm{mL} \mathrm{RE}$ upregulated $\mathrm{ER} \alpha$ and $\mathrm{ER} \beta$ expression in immortalized NHEK (Figure 7(A), Figure $7(B)$ ), and $80 \mu \mathrm{g} / \mathrm{mL} \mathrm{RE} \mathrm{promoted} \mathrm{cell} \mathrm{proliferation} \mathrm{(Figure} 7(\mathrm{C})$ ). The findings from NHEK coincided with the effect of ER upregulation on NHDF. These results suggest that $\mathrm{RE}$ activates epidermal and dermis.

In addition, ER expression in the skin model was increased by RE in a time-dependent manner. Interestingly, ER expression was observed in the stratum corneum from the basal layer of ER $\alpha$ and in the stratum corneum from the granular layer of $\mathrm{ER} \beta$ (Figure 8(A)). Keratinocytes in the granular layer of epi- 
dermis express certain proteins, including loricrin, involucrin, and cytokeratin-10. Estrogen promotes epidermal differentiation by binding to the ER [10] [11] [12] [17]. In addition, epidermal cornification is a programmed cell death of the epidermis that occurs during the transition between the granular layer and the stratum corneum, and keratinocytes of the epidermis lose their nuclei and other organelles due to cornification, forming an essential barrier for the skin [29] [30] [31]. ER $\alpha$ homodimers promote cell growth by promoting the activation of cyclin $\mathrm{D}$ and the production of growth factors. In contrast, homodimers of $\operatorname{ER} \beta$ and heterodimers of $\operatorname{ER} \alpha$ - $\operatorname{ER} \beta$ induce cell death by inactivating cyclin $\mathrm{D}$ and decreasing growth factor production [10] [11] [19] [20]. Therefore, the proliferation and differentiation of keratinocytes appears to be promoted by the increase in ER $\alpha$ homodimer in the basal to the granular layer, and the cornification of epidermis may be promoted by the formation of $\operatorname{ER} \beta$ homodimers or $\operatorname{ER} \alpha$-ER $\beta$ heterodimers in the granular layer. These observations suggest that a balance between $\operatorname{ER} \alpha$ and $\operatorname{ER} \beta$ regulates epidermal differentiation and cornification. To assess this, we evaluated the effects of epidermal differentiation markers loricrin, involucrin, and cytokeratin-10 and found that RE promoted the expression of these three proteins when compared to their expression in the vehicle (Figure 8(B)). These results support the notion that ER upregulation is important for the maintenance of epidermal function.

In conclusion, $\mathrm{RE}$ is considered to be a promising cosmetic ingredient that prevents skin aging because it upregulates ER expression, which is decreased by aging and UV, and promotes estrogen activity, ECM production, and epidermal differentiation.

\section{Conflicts of Interest}

The authors declare no conflicts of interest regarding the publication of this paper.

\section{References}

[1] Uranoa, R., Sakabe, K., Seiki, K. and Ohkido, M. (1995) Female Sex Hormone Stimulates Cultured Human Keratinocyte Proliferation and Its RNA- and Protein-Synthetic Activities. Journal of Dermatological Science, 9, 176-184. https://doi.org/10.1016/0923-1811(94)00375-O

[2] Bentley, J.P., Brenner, R.M., Linstedt, A.D., West, N.B., Carlisle, K.S., Rokosova, B.C. and Donald, N.M. (1986) Increased Hyaluronate and Collagen Biosynthesis and Fibroblast Estrogen Receptors in Macaque Sex Skin. Journal of Investigative Dermatology, 87, 668-673. https://doi.org/10.1111/1523-1747.ep12456427

[3] Thornton, M.J. (2013) Estrogens and Aging Skin. Dermato-Endocrinology, 5, 264-270. https://doi.org/10.4161/derm.23872

[4] Masuda, Y., Hirao, T. and Mizunuma, H. (2013) Improvement of Skin Surface Texture by Topical Estradiol Treatment in Climacteric Women. Journal of Dermatological Treatment, 24, 312-317. https://doi.org/10.3109/09546634.2011.643218

[5] Watson, C.S., Jeng, Y.J. and Kochukov, M.Y. (2008) Nongenomic Actions of Estradiol Compared with Estrone and Estriol in Pituitary Tumor Cell Signaling and Pro- 
liferation. The FASEB Journal, 22, 3328-3336. https://doi.org/10.1096/fj.08-107672

[6] Tee, M.K., Rogatsky, I., Foster, C.T., Cvoro, A., An, J., Christy, R.J., Yamamoto, K.R. and Leitman, D.C. (2004) Estradiol and Selective Estrogen Receptor Modulators Differentially Regulate Target Genes with Estrogen Receptors $\alpha$ and $\beta$. Molecular Biology of the Cell, 15, 1262-1272. https://doi.org/10.1091/mbc.e03-06-0360

[7] Paech, K., Webb, P., Kuiper, G.G., Nilsson, S., Gustafsson, J.A., Kushner, P.J. and Scanlan, T.S. (1997) Differential Ligand Activation of Estrogen Receptors ERalpha and ERbeta at AP1 Sites. Science, 277, 1508-1510. https://doi.org/10.1126/science.277.5331.1508

[8] McNamara, A.V., Adamson, A.D., Dunham, L.S.S., Semprini, S., Spiller, D.G., McNeilly, A.S., Mullins, J.J., Davis, J.R.E. and White, M.R.H. (2016) Role of Estrogen Response Element in the Human Prolactin Gene: Transcriptional Response and Timing. Molecular Endocrinology, 30, 189-200.

https://doi.org/10.1210/me.2015-1186

[9] Schultz, G.S. and Wysocki, A. (2009) Interactions between Extracellular Matrix and Growth Factors in Wound Healing. Wound Repair and Regeneration, 17, 153-162. https://doi.org/10.1111/j.1524-475X.2009.00466.x

[10] Liang, J. and Shang, Y. (2013) Estrogen and Cancer. Annual Review of Physiology, 75, 225-240. https://doi.org/10.1146/annurev-physiol-030212-183708

[11] Nozoe, T., Oyama, T., Takenoyama, M., Hanagiri, T., Sugio, K. and Yasumoto, K. (2007) Significance of Immunohistochemical Expression of Estrogen Receptors $\alpha$ and $\beta$ in Squamous Cell Carcinoma of the Esophagus. Clinical Cancer Research, 13, 4046-4050. https://doi.org/10.1158/1078-0432.CCR-07-0449

[12] Miyagawa, S. and Iguchi, T. (2015) Epithelial Estrogen Receptor 1 Intrinsically Mediates Squamous Differentiation in the Mouse Vagina. Proceedings of the National Academy of Sciences of the United States of America, 112, 12986-12991. https://doi.org/10.1073/pnas.1513550112

[13] Inoue, T., Miki, Y., Abe, K., Hatori, M., Hosaka, M., Kariya, Y., Kakuo, S., Fujimura, T., Hachiya, A., Aiba, S. and Sasano, H. (2011) The Role of Estrogen-Metabolizing Enzymes and Estrogen Receptors in Human Epidermis. Molecular and Cellular Endocrinology, 344, 35-40. https://doi.org/10.1016/j.mce.2011.06.015

[14] Ishunina, T.A., Kruijver, F.P., Balesar, R. and Swaab, D.F. (2000) Differential Expression of Estrogen Receptor Alpha and Beta Immunoreactivity in the Human Supraoptic Nucleus in Relation to Sex and Aging. The Journal of Clinical Endocrinology and Metabolism, 85, 3283-3291. https://doi.org/10.1210/jcem.85.9.6826

[15] Kubo, M., Asano, T., Mathuda, H., Yutani, S. and Honda, S. (1996) Studies on Rehmanniae Radix. III. The Relation between Changes of Constituents and Improvable Effects on Hemorheology with the Processing of Roots of Rehmannia glutinosa. Yakugaku Zasshi, 116, 158-168.

https://doi.org/10.1248/yakushi1947.116.2_158

[16] Sevrain, S.V., Yaar, M., Cantatore, J., Traish, A. and Gilchrest, B.A. (2004) Estradiol Induces Proliferation of Keratinocytes via a Receptor Mediated Mechanism. FASEB Journal, 18, 1252-1254. https://doi.org/10.1096/fj.03-1088fje

[17] Son, H.J., Kim, N., Song, C.H., Lee, S.M., Lee, H.N. and Surh, Y.J. (2020) $17 \beta$-Estradiol Reduces Inflammation and Modulates Antioxidant Enzymes in Colonic Epithelial Cells. The Korean Journal of Internal Medicine, 35, 310-319. https://doi.org/10.1096/fj.03-1088fje

[18] Hirao-Suzuki, M., Takeda, S., Okuda, K., Takiguchi, M. and Yoshihara, S. (2019) Repeated Exposure to 4-Methyl-2,4-bis(4-hydroxyphenyl) pent-1-ene (MBP), an 
Active Metabolite of Bisphenol A, Aggressively Stimulates Breast Cancer Cell Growth in an Estrogen Receptor $\beta(\mathrm{ER} \beta)$-Dependent Manner. Molecular Pharmacology, 95, 260-268. https://doi.org/10.1124/mol.118.114124

[19] Paruthiyil, S., Parmar, H., Kerekatte, V., Cunha, G.R., Firestone, G.L. and Leitman, D.C. (2004) Estrogen Receptor $\beta$ Inhibits Human Breast Cancer Cell Proliferation and Tumor Formation by Causing a G2 Cell Cycle Arrest. Cancer Research, 64, 423-428. https://doi.org/10.1158/0008-5472.CAN-03-2446

[20] Omoto, Y. and Iwase, H. (2015) Clinical Significance of Estrogen Receptor $\beta$ in Breast and Prostate Cancer from Biological Aspects. Cancer Science, 106, 337-343. https://doi.org/10.1111/cas.12613

[21] Sakiyama, R., Fukuta, K., Matsumoto, K., Furukawa, M., Takahashi, Y. and Nakamura, T. (2007) Stimulation of Hepatocyte Growth Factor Production by Heparin-Derived Oligosaccharides. The Journal of Biochemistry, 141, 653-660. https://doi.org/10.1093/jb/mvm067

[22] Kawada, A., Hiura, N., Shiraiwa, M., Tajima, S., Hiruma, M., Hara, K., Ishibashi, A. and Takahara, H. (1997) Stimulation of Human Keratinocyte Growth by Alginate Oligosaccharides, a Possible Co-Factor for Epidermal Growth Factor in Cell Culture. FEBS Letters, 408, 43-46. https://doi.org/10.1016/S0014-5793(97)00386-4

[23] Jones, S.M. and Kazlauskas, A. (2001) Growth Factor-Dependent Signaling and Cell Cycle Progression. FEBS Letters, 490, 110-106.

https://doi.org/10.1016/S0014-5793(01)02113-5

[24] Gross, S.M. and Rotwein, P. (2016) Unraveling Growth Factor Signaling and Cell Cycle Progression in Individual Fibroblasts. Journal of Biological Chemistry, 291, 14628-14638. https://doi.org/10.1074/jbc.M116.734194

[25] Mukherjee, P., Winter, S.L. and Alexandrow M.G. (2010) Cell Cycle Arrest by Transforming Growth Factor beta1 near G1/S Is Mediated by Acute Abrogation of Prereplication Complex Activation Involving an Rb-MCM Interaction. Molecular and Cellular Biology, 30, 845-856. https://doi.org/10.1128/MCB.01152-09

[26] Ohtani, N. (2014) Cellular Senescence and Chronic Inflammation. Japanese Journal of Clinical Immunology, 37, 390. https://doi.org/10.2177/jsci.37.390

[27] Misawa, T., Tanaka, Y., Okada, R. and Takahashi, A. (2020) Biology of Extracellular Vesicles Secreted from Senescent Cells as Senescence-Associated Secretory Phenotype Factors. Geriatrics \& Gerontology International, 20, 539-546. https://doi.org/10.1111/ggi.13928

[28] Bai, L., Shi, G.Y., Yang, Y.J., Chen, W., Zhang, L.F. and Qin, C. (2018) Rehmannia glutinosa Exhibits Anti-Aging Effect through Maintaining the Quiescence and Decreasing the Senescence of Hematopoietic Stem Cells. Animal Models and Experimental Medicine, 1, 194-202. https://doi.org/10.1002/ame2.12034

[29] Komuves, L.G., Hanley, K., Jiang, Y., Elias, P.M., Williams, M.L. and Feingold, K.R. (1998) Ligands and Activators of Nuclear Hormone Receptors Regulate Epidermal Differentiation during Fetal Rat Skin Development. Journal of Investigative Dermatology, 111, 429-433. https://doi.org/10.1046/j.1523-1747.1998.00296.x

[30] Candi, E., Schmidt, R. and Melino, G. (2005) The Cornified Envelope: A Model of Cell Death in the Skin. Nature Reviews Molecular Cell Biology, 6, 328-340. https://doi.org/10.1038/nrm1619

[31] Nicotera, P. and Melino, G. (2007) Caspase-14 and Epidermis Maturation. Nature Cell Biology, 9, 621-622. https://doi.org/10.1038/ncb0607-621 